\title{
Impact of low intensity summer rainfall on $E$. coli-discharge event dynamics with reference to sample acquisition and storage
}

4

5

6

7

8

9

10

11

12

13

14

15

16

17

18

19

20

21

22

23

24

25

26

27

28

29

30

31

32

33

34

35

36
David M Oliver ${ }^{1 *}$, Kenneth Porter $^{1}$, A. Louise Heathwaite ${ }^{2}$, Ting Zhang ${ }^{3}$ \& Richard S Quilliam ${ }^{1}$

\author{
1 Biological \& Environmental Sciences, University of Stirling, Stirling, FK9 4LA, UK \\ 2 Lancaster Environment Centre, Lancaster University, Lancaster LA1 4YQ, UK \\ $3 \mathrm{CEH}$ Wallingford, Oxfordshire, OX10 8BB, UK
}


Understanding the role of different rainfall scenarios on faecal indicator organism (FIO) dynamics under variable field conditions is important to strengthen the evidence-base on which regulators and land managers can base informed decisions regarding diffuse microbial pollution risks. We sought to investigate the impact of low intensity summer rainfall on E. coli - discharge $(Q)$ patterns observed at the headwater catchment scale in order to provide new empirical data on FIO concentrations observed during base-flow conditions. In addition, we evaluated the potential impact of using automatic samplers to collect and store freshwater samples for subsequent microbial analysis during summer storm sampling campaigns. The temporal variation of $E$. coli concentrations with $\mathrm{Q}$ was captured during six events throughout a relatively dry summer in central Scotland. The relationship between $E$. coli concentration and $Q$ was complex with no discernible patterns of cell emergence with $Q$ that were repeated across all events. On several occasions an order of magnitude increase in E. coli concentrations occurred even with slight increases in $Q$, but responses were not consistent and highlighted the challenges of attempting to characterise temporal responses of $E$. coli concentrations relative to $Q$ during low intensity rainfall. Cross-comparison of $E$. coli concentrations determined in water samples using simultaneous manual grab and automated sample collection was undertaken with no difference in concentrations observed between methods. However, the duration of sample storage within the autosampler unit was found to be more problematic in terms of impacting on the representativeness of microbial water quality, with unrefrigerated autosamplers exhibiting significantly different concentrations of $E$. coli relative to initial samples after 12 hours storage. The findings from this study provide important empirical contributions to the growing evidence-base in the field of catchment microbial dynamics.

Keywords: autosampler; climate change; diffuse pollution; faecal indicator organism; storm event; water quality 


\section{Introduction}

Recognition of the implications of diffuse water pollution from agriculture on the freshwater environment has improved significantly over the last few decades. However, the spatial and temporal complexity of pollutant losses from land to water continues to challenge our understanding of contaminant transfer processes across a range of spatial and temporal scales (Harris \& Heathwaite, 2012; Haygarth et al., 2012). The evidence-base that underpins current understanding is more developed for some pollutants than for others, for example, our knowledge of diffuse pollution is more advanced for nutrients than for microbial pollutants, such as pathogens, often interpreted through analysis of faecal indicator organisms (FIOs) (Oliver et al., 2010; Kay et al., 2008). Regulatory monitoring of FIOs is undertaken throughout the world to ensure water quality complies with health-related standards and associated legislation. Understanding how agriculture impacts microbial water quality when coupled with contrasting climatic and environmental conditions is critical in order to design better mitigation strategies to protect surface waters and further improve microbial water quality (Fish et al., 2014).

Observations have shown that over $90 \%$ of the catchment input of microbial contamination occurs after rainfall-runoff, usually following storm events (McKergow and Davies-Colley, 2010; Kay et al., 2007; Kay et al., 1999), with at least an order of magnitude difference in FIO concentrations between base and storm flows commonly reported (Kay et al., 2010). However, there has been comparatively little work exploring the role of low intensity rainfall (e.g. $<4 \mathrm{~mm} \mathrm{hr}^{-1}$; MET Office, 2009), and the impact these events may have on microbial concentrations in freshwater when interspersed during prolonged dry weather spells. The influence and timing of smaller rainfall events on in-stream FIO concentrations could be significant during a drier summer season given the potential for bacterial transfer through and across cracking and crusted soils coupled with high FIO source loading on pasture from direct defecation by grazing livestock and increased manure and slurry applications to land (Oliver et al., 2005a). Summertime also represents a key sampling 
period given seasonally important policy drivers, e.g. the EU Bathing Waters Directive (CEC, 2006). Furthermore, the typical base-flow conditions in streams and rivers during summer periods reduce the opportunity for dilution of FIOs entering waterbodies following summer rainfall. This may be problematic at the local scale (e.g. cattle drinking from streams and opportunities for within-herd pathogen cycling), but when scaling up to the larger catchment network the overall FIO load will be reduced because of low discharge (Q). However, the lack of empirical observations to confirm or refute the importance of these 'minor' rainfall events in changing $E$. coli-discharge dynamics during dominantly dry weather warrants further attention; particularly as such occurrences may become more common across parts of the UK and Northern Europe under a changing climate (Arnell et al., 2015).

While year-on-year variability in hydrological responses in catchments (e.g. Meays et al., 2006) and seasonal variations in stream Q (e.g. Wilkes et al., 2009; Kay et al., 2008) can impact on water quality, interpretation of the microbial signature in aquatic samples may also be influenced by monitoring strategy, e.g. choice of sampling frequency or method. The monitoring of pollutant flux dynamics within catchment systems tends to generate a timeseries in which the sampling interval determines the quality of capture of storm events. Logistically, the intensive capture of samples throughout a storm hydrograph is made easier through the use of an automatic sampler. Approaches to water quality monitoring are guided by cost constraints and availability of resources. For microbial parameters, the aseptic grab sampling method is unequivocal for providing a water sample suitable for FIO quantification. Compared with automated alternatives this approach is demanding in terms of staff resource, particularly during high frequency sampling, e.g. during storm events. Water collected by an autosampler allows the acquisition of representative samples for subsequent analysis of many physical and chemical parameters such as suspended sediment and most nutrient fractions (e.g. Owen et al., 2012; Granger et al., 2011; Bilotta et al., 2010). However, the use of autosamplers is perhaps more contested when collecting samples for microbial water quality analysis, with a degree of scepticism associated with the quality of data 
resulting from samples that have been held in stasis for prolonged periods, or cannot be guaranteed to have been collected aseptically (Hathaway et al., 2014). This is because: 1) the reception bottle in an autosampler unit will be non-sterile at the point of sample collection, 2) there is an opportunity for microbial cross-contamination between samples during collection via the inlet hose, and 3) some microbial die-off will be likely depending on sample storage times in the autosampler unit.

Despite these limitations a number of studies have used autosamplers (equipped with and without refrigeration units for sample storage) for microbial water quality assessment across a range of temperature conditions (e.g. Guber et al. 2011; Wilkinson et al. 2011; Vinten et al. 2008; Oliver et al. 2005b; Solo-Gabriele et al. 2000). Ghazaleh et al. (2014) evaluated the effect of storage time on FIOs in estuarine water held in an autosampler with a view that little data exists on 'bottle-effects' during the first 24 hours on containment. Ferguson (1994) used a refrigerated autosampler to specifically investigate differences in FIOs from manually versus automatically derived water samples, and concluded that concentrations of FIOs in samples taken from autosamplers differed from those taken manually, but that the size of the difference was negligible for the purpose of environmental monitoring. Importantly however, this study was based on samples collected during dry weather days only. Therefore, we still lack an understanding of the role of different rainfall scenarios on FIO dynamics under variable field conditions, which is vital for strengthening the evidence-base on which regulators and land managers can base informed decisions. The role of low intensity rainfall could be significant for localised in-stream FIO concentrations particularly during the warmer, drier summers that are becoming more commonplace in the UK (Arnell et al., 2015). Thus, the aim of this study was to: (i) investigate the temporal patterns of $E$. coli emergence with $Q$ from a small headwater catchment throughout an dry summer in central Scotland; and (ii) evaluate the impact of different methods of sample acquisition and storage on $E$. coli concentrations. 


\section{Materials and methods}

\subsection{Study catchment}

This study investigated microbial water quality in a stream draining from a $0.37 \mathrm{~km}^{2}$ headwater catchment located in Stirlingshire, Central Scotland (Figure 1). The catchment area is characterised by low density livestock and arable farming with a small amount of mixed woodland. Specifically, land use is categorised as $50.0 \%$ improved grassland, $25.2 \%$ arable, $16.6 \%$ rough grazing and $8.2 \%$ woodland. A number of fields adjacent to the monitoring point were grazed by ca. 20 sheep, and a field at the source of the stream was grazed by 12 dairy cows throughout the monitoring period. All livestock had direct access to the watercourse for drinking. The bedrock at this site is described as sandstone with superficial deposits of Devensian Diamicton with raised tidal flat deposits of silt and clay also present. The soil type is typical of brown forest soils with gleying and is made up of the Oglegarth, Balvorist and Lennieston soil units, which represent noncalcareous gley, peaty gley and humus-iron podzol, respectively (Soil Survey of Scotland Staff, 1970-1987). The slope from the point of maximum elevation to the catchment outlet represents a gradient of $3.4 \%$.

\section{INSERT FIGURE 1 HERE}

\subsection{In situ hydrological monitoring}

A V-notch weir was installed at the designated catchment outlet to provide monitoring infrastructure for continuous $Q$ measurements and associated water quality parameters, e.g. turbidity. The gauging station contained a CR800 datalogger connected to an ARG100 rain gauge, OBS 3 turbidity meter, SOP18X solar panel and a PDCR1830 pressure transducer (all Campbell Scientific, Loughborough, UK). The rain gauge provided measurement of daily rainfall and rainfall intensity; the turbidity meter provided a continuous record of in-stream 
172 turbidity and the pressure transducer, built into a stilling well, recorded water depth for later

173 conversion to stream Q. Stage height was converted to $Q$ using an established rating curve

174 for the site. The two-year mean discharge at the site is $140 \mathrm{Ls}^{-1}$. The Campbell datalogging equipment was also linked to an unrefrigerated automatic ISCO 3700 water sampler (Teledyne Isco Inc., Lincoln, USA) for capture of storm-related water samples.

\subsection{Water sample collection during rainfall events}

During rainfall events water samples were collected for microbial analysis using an automatic sampler. Bottles used in the autosampler were sterilised by autoclaving (20 min $\left.121^{\circ} \mathrm{C}, 1.5 \mathrm{bar}\right)$ and were deployed in the field as close to a storm event as possible to minimise contamination. Field technicians were notified of any autosampler activity through an SMS message sent via a modem connected to the datalogging equipment on-site. Samples were therefore retrieved with minimal delay and all samples returned to the laboratory in a cool-box and analysed within 12 hours of their collection. concentrations in response to stream-flow. The ISCO autosampler was programmed to respond to $Q$ thresholds that, when exceeded, triggered the sampler on a time-proportional basis. The stage height at which the sampler was triggered was variable and pre-defined to ensure that coverage of a range of events was achieved for different antecedent flow conditions. On occasion the autosampler was triggered manually in anticipation of a forecast rainfall event. Once triggered, water samples were collected on a time-proportional basis events were triggered by flow exceedance and three triggered manually. appropriate to the forecasted 'storm' event. This strategy was flexible meaning that obtaining samples was not solely reliant on flow exceedance and thresholds were manipulated to take account of changing base levels and lack of $Q$ response due to low rainfall. In total, three

\subsection{Microbiological analysis}



determine bacterial concentrations (EA, 2009). Each water sample was vacuum-filtered with $20 \mathrm{~mL}$ of phosphate buffered saline (PBS) through a $0.45 \mu \mathrm{m}$ cellulose acetate membrane (Sartorius Stedim Biotech., Goettingen, Germany). The membrane was then aseptically transferred to the surface of a plate containing Membrane Lactose Glucuronide Agar (MLGA) (CM1031, Oxoid, Basingstoke, UK), inverted and incubated at $37^{\circ} \mathrm{C}\left( \pm 0.2^{\circ} \mathrm{C}\right)$ for $18-$ $24 \mathrm{~h}$ for the determination of presumptive E. coli colonies. For each analysis, $100 \mathrm{~mL}, 10 \mathrm{~mL}$, $1 \mathrm{~mL}$ of sample were filtered, with further serial 1:10 dilutions made as appropriate to ensure capture of between 20 to 200 colony forming units (CFU). Method blanks were regularly used to assess aseptic technique and to evaluate sterilisation efficiency between samples. All sample analysis was performed in duplicate.

\subsection{Autosampler versus grab sampling}

A 'grab versus autosampler' comparative study was also conducted to establish whether the autosampler unit impacted on the microbial parameters being enumerated (e.g. carry-over contamination in sample inlet hose or reduced $E$. coli numbers through competition with other bacteria). On 20 occasions, under different flow conditions, the autosampler was triggered for sample collection and an equivalent grab sample taken from the same point in the stream. Samples were not stored in the autosampler but instead removed immediately to enable a determination of the role of carry-over contamination as opposed to die-off (see Section 2.6). In parallel, an additional 22 comparative autosampler and grab samples were collected from a second headwater catchment site in Lancashire, England, in order to augment the data and provide a cross comparison to samples obtained from a stream under much higher flows during wetter weather. These 22 samples were collected from across multiple flow conditions during 7 different monitored events. 
The impact of storage conditions, such as temperature and duration, on the microbial

quality of samples held within autosamplers was investigated to complement the 'grab versus autosampler' comparative study. We investigated the die-off of $E$. coli concentrations in stored samples held under both ambient and refrigerated $\left(4^{\circ} \mathrm{C}\right)$ autosampler conditions in July. Our approach was to mimic the collection of water samples that had been heavily contaminated with faecal material and therefore to inoculate bottles with sufficiently high $E$. coli starting concentrations to enable determination of a die-off profile over time but also reflect realistic field conditions. In total, 8 litres of stream water was artificially contaminated with $\sim 1 \mathrm{~kg}$ of fresh ovine faeces, mixed, and then $900 \mathrm{~mL}$ distributed to each replicate sterile autosampler bottle before being sealed and placed within the autosampler unit. Four replicate bottles were used in both the ambient (standard ISCO 3700 stored outside) and refrigerated (ISCO bottles kept within a coldroom at $4^{\circ} \mathrm{C}$ ) treatments. To determine the temperature profile within the ambient treatment we installed a DS1921G Thermochron ibutton temperature logger (iButtonLink, WI, USA) within the body of the autosampler unit, where the water samples were stored. Bottles were shaken briefly prior to sampling and a 20 $\mathrm{mL}$ volume was sampled from the bottles after $0,5,24,48,72,96,120,144,192$ and 241 hours and the water analysed for E. coli as described above.

\subsection{Statistical analysis}

All E. coli counts underwent $\log _{10}$ transformation prior to statistical analysis. To determine whether there was any difference in the CFUs reported using autosampler versus grab sampling methods we used the Altman-Bland graphical method coupled with a followup correlation and paired $t$-test (Altman \& Bland, 1983). For analysis of die-off curves, different phases of cell population dynamics were identified from a visual inspection of the curves and categorised as: 1) slow die-off and 2) rapid die-off. Linear least squares regression was used to find the rate of change for replicates within each phase of population change. A Wilcoxon signed rank test was used to determine whether there was a significant 
difference in the rate of change of cell numbers between treatments. All statistical tests were performed in the statistical package ' $R$ ' v 2.15 .2 (2012).

\section{Results}

\subsection{E. coli - $Q$ relationships}

This study captured the temporal response of $E$. coli concentrations with $Q$ from a small headwater catchment during six rain events during the relatively dry summer of 2013 in central Scotland (Fig 2 and Fig 4a-f). The corresponding ambient temperature profile of the monitoring period is shown in Figure 3. These six events accommodated a range of peak $Q$ with the smallest event reaching a maximum $Q$ of $0.03 \mathrm{Ls}^{-1}$ (event $2 ; 15^{\text {th }}$ June) and the largest event reaching a maximum $Q$ of $1.04 \mathrm{Ls}^{-1}$ (event $1 ; 27^{\text {th }}$ May). All peak $Q$ values recorded were therefore low and approximately two orders of magnitude lower than the mean $Q$ at this site over a typical hydrological year $\left(140 \mathrm{Ls}^{-1}\right)$, with rain events failing to generate substantial stream flow and little hydrological response from the catchment during the summer monitoring period. Table 1 provides summary characteristics for each of the six events. The rainfall associated with event 1 resulted in a classic storm hydrograph response, with a steep rising limb and a gentle falling limb; although the peak $Q$ was low at just over 1 $\mathrm{Ls}^{-1}$, this was not unusual for a small headwater stream such as this during summer baseflow conditions. Hydrological activity was minimal over the course of the next 18 days and the peak $Q$ of event 2 provided a contrasting and poorly defined hydrograph and pollutograph response, whilst hydrographs of the remaining storm events that were monitored had only marginally improved definition. The event associated with the highest peak concentration of $E$. coli occurred in July (event 4; $2855 \mathrm{CFU} / 100 \mathrm{~mL}$ ) despite the event generating a peak $Q$ of only $0.087 \mathrm{Ls}^{-1}$. The lowest peak concentration of $E$. coli (118 $\mathrm{CFU} / 100 \mathrm{~mL}$ ) was associated with the event that generated the largest peak $\mathrm{Q}$ (event 1). The two events captured in July occurred in close succession only two days apart and this general period of elevated hydrological activity appeared to generate much higher 
concentrations of $E$. coli in water exported from the catchment. Concentrations recorded during events 4 and 5 were an order of magnitude greater than previous events although the microbial signatures did not follow a clear pattern with $Q$ and no correlation was observed between $Q$ and $E$. coli during these events. The peak instantaneous load for each event was also calculated to take into account the low flow impact on $E$. coli export from the headwater catchment (see Table 1). If the contributing area of the catchment is taken into account then the maximum instantaneous load observed over all six events was $182 \mathrm{CFU} \mathrm{s}{ }^{-1} \mathrm{ha}^{-1}$.

\section{INSERT FIGURE 2, 3 \& 4 HERE}

INSERT TABLE 1 HERE

290

291

In-situ turbidity readings for the six sampling dates varied from as low as 1 NTU through to 132 NTU (Table 1) and overall a relatively weak (but significant) correlation was observed between $E$. coli and turbidity observed across all events $(r=0.36 ; P<0.001)$. Event 1 (lowest E. coli peak and highest Q) recorded the lowest turbidity values throughout the event. The highest turbidity values were associated with event 5 which registered the $2^{\text {nd }}$ largest peak of $E$. coli $(2350 \mathrm{CFU} / 100 \mathrm{~mL})$. No difference $(P>0.05)$ was evident in $E$. coli concentrations determined during the rising limb versus the falling limb of storm hydrographs. The relationship between $E$. coli concentration and $Q$ was explored across these six events but appeared complex with no consistent discernable patterns of cell emergence with $Q$ and no clear trends in hysteresis observed.

\subsection{Autosampler vs Grab sampling}

A total of 42 comparative samples were collected simultaneously via aseptic grab sampling and using an autosampler collection hose connected to an ISCO 3700 automatic sampler. The 42 samples were collected over the course of multiple events from two different sites in the UK. Results of this cross comparison study are presented as a scatter 
plot in Figure 5. In order to test for differences between the two methods it was necessary to

309 first plot the difference between the CFUs obtained via the two different methods (e.g. CFU

$310-\mathrm{CFU}_{2}$ ) versus the average of the CFUs produced using both methods (e.g. $\left[\mathrm{CFU}_{1}+\mathrm{CFU}_{2}\right] /$

311 2) (Fig 6), and to then determine, through correlation, whether we can assume

312 independence of the between-method differences and the size of the measurements (Altman

313 \& Bland, 1983). The correlation coefficient of the data presented in Figure 6 was found to be

$314-0.1(P>0.05)$ suggesting no significant association linking between-method differences and the size of the measurements. With independence confirmed, a paired $t$-test confirmed that there was no significant difference $(P>0.05)$ between the CFUs observed by the two alternative methods of sample acquisition.

INSERT FIGURE 5 and 6 HERE

\subsection{Effect of autosampler storage on E. coli die-off}

Three distinct phases of $E$. coli population dynamics were observed within samples stored under both ambient and refrigerated conditions inside an autosampler unit (regrowth; slow die-off; rapid die-off). However, a 'growth rate' for the treatments is not presented because of the limited availability of sampling points during this phase. This initial population increase prior to two-stage $1^{\text {st }}$-order decline (Figure 7) was more pronounced for E. coli kept under ambient conditions (24 h) compared to those kept under refrigerated conditions (5 h). The magnitude of increase under ambient temperature conditions was equivalent to 0.33 $\log _{10} E$. coli, whereas for the refrigerated treatment the magnitude of increase measured $0.14 \log _{10} E$. coli (see Fig 7). Table 2 shows the average rate of change for each of the two die-off phases of the two temperature treatments and the results of a Mann-WhitneyWilcoxon signed rank test used to determine whether these rates of change differed across treatments. The rate of die-off accelerated in both treatments after $120 \mathrm{~h}$, with die-off rate occurring more rapidly in the refrigerated treatment during the final die-off phase $(P<0.05)$. 
were also investigated for both temperature treatments. Under refrigerated conditions a significant difference $(P<0.05)$ in $E$. coli counts was only observed after 120 hours of storage (though at 96 hours $P=0.06$ ). Concentrations of $E$. coli stored under ambient conditions showed no significant difference over the first 5 hours of storage relative to the initial sample, but following 12 hours $E$. coli concentration had become significantly higher ( $P$ $<0.05)$ than the initial input.

\section{INSERT FIGURE 7 HERE}

INSERT TABLE 2 HERE

\section{Discussion}

4.1 E. coli concentrations in response to minor rainfall events

Large storm events are known to mobilise and transfer diffuse microbial pollutants from agricultural land to water, although the extent of this is dependent upon catchment characteristics such as land use, topography and soil type, together with rainfall patterns and antecedent soil moisture (McKergow \& Davies-Colley, 2010). Our knowledge of how these factors interact to affect diffuse microbial pollution is limited because of the complexity and heterogeneity of catchment systems (Winter et al., 2011; Fish et al., 2009). The impact of relatively small but persistent rainfall events on microbial water quality during warmer and typically drier summer periods is one such scenario that has evaded investigation. Our results have highlighted a number of general observations about the subtleties of microbial pollution during intermittent rainfall throughout dry weather periods, and have provided some insight into how contrasting event characteristics across a typical mixed land use area can regulate $E$. coli dynamics. While rainfall did occur during the study period, the accompanying increase in $Q$ was minor compared to studies focusing on the monitoring of large storm driven pulses of microbial pollution through catchment systems (e.g. Wyer et al., 2010).

Data from the six monitored events suggest that in the water column of a small agricultural stream, even very small increases in $Q$ can give rise to elevated $E$. coli 
concentrations. Previous reports have demonstrated that levels of FIOs can increase by at least an order of magnitude during 'event' conditions (Kay et al., 2010). Importantly, our results, e.g. 'event 1', support the scalability of this 'rule' from large catchments and major intense storms down to much smaller headwater catchments and events driven by more modest rainfall. Although the hydrograph for 'event 2' accommodated a much reduced peak $Q$ this is not surprising given the consistently low baseflow conditions prior to this event despite the antecedent rainfall being actually higher than for the previous event. Little, if any, of that rainfall however, generated any noticeable impact on the baseflow $Q$ of the stream, probably due to the lower intensity precipitation distributed over a longer timeframe resulting in little external hydrological input being successfully delivered to the stream. Despite 'event 2' converting to a weak hydrograph signature, the increase in E. coli concentration was around five times higher than during 'event 1'. The slight increase in flow from a very low baseflow condition would probably have been insufficient to resuspend the uppermost layer of streambed sediment which can, if conditions allow, provide a source of higher $E$. coli concentrations relative to the water column (Pachepsky \& Shelton, 2011; Muirhead et al., 2004). Given the scale of this 'event' it is also unlikely that carriage of bacterial cells from the surrounding land contributed to this increase. Thus, the increase in E. coli for 'event 2' most likely reflects the deposition of fresh faecal material into the stream either by cattle further upstream or by sheep grazing in fields adjacent to the monitoring point. Furthermore, the frequency of animal activity in and around the watercourse is likely to have increased during the warm weather (see increasing temperatures throughout the study period in Fig 3) leading to more defecation in close proximity to the stream, or directly into the water (White et al., 2001).

'Event 3' resulted in a similar, though slightly more pronounced, hydrograph and in turn a more defined increase in E. coli concentrations relative to 'event 2'. This repeated pattern could suggest that an in-stream store of E. coli, possibly held within a faecal deposit, was being eroded over time with increases in Q. However, more controlled laboratory-based 
mobilisation experiments (e.g. Hodgson et al., 2009) and flume studies (e.g. McDaniel et al., 2013) would be needed to determine critical thresholds of $E$. coli release both from sediment, and also from submerged faecal deposits. The exact reasons for the elevated microbial counts recorded during events 4 and 5 are unclear but certainly the rainfall distribution between event 3 and 4 had increased, which resulted in an increased baseflow Q. Elevated turbidity would provide a useful surrogate to indicate any direct faecal pollution; however, while turbidity was relatively high for events 4 and 5 other events also exhibited high turbidity but did not show the same response in $E$. coli concentration. This adds further evidence to suggest that while turbidity can, under certain circumstances, serve as a useful proxy for microbial water quality it is perhaps not as robust a surrogate as sometimes assumed via anecdotal accounts of diffuse microbial pollution. Others have raised similar concerns of the usefulness of turbidity as a surrogate for $E$. coli presence given that spatially distinct sources of E. coli and turbidity can exist in catchment systems (McKergow \& Davies Colley, 2010), though this is often more of an issue at larger catchment scales.

The calculation of peak instantaneous loads is crucial for considering the overall impact of varying storm typologies on microbial water quality. For example, the combination of $Q$ and $E$. coli concentrations observed during event 5 resulted in the highest recorded peak instantaneous $E$. coli load at this site (6744 CFU s${ }^{-1}$, equivalent to $\left.182 \mathrm{CFU} \mathrm{s}^{-1} \mathrm{ha}^{-1}\right)$. This relatively small microbial load was associated with the highest rainfall rates observed over the study period but still represented a relatively minor rainfall event during low flow stream conditions. In comparison, E. coli load from grazed grassland following a more intense rainfall event, with daily rainfall in excess of $20 \mathrm{~mm} \mathrm{day}^{-1}$, resulted in $1.25 \times 10^{6} \mathrm{CFU}$ $\mathrm{s}^{-1} \mathrm{ha}^{-1}$ (Oliver et al., 2005b).

\subsection{Evaluating the role of autosamplers for microbial water quality assessment}

There are reported differences in microbial concentrations determined in samples collected manually versus those obtained using autosamplers, although these differences 
418 were considered too small to be of practical significance (Ferguson, 1994). Likewise, our 419 analysis also showed no significant difference between autosampler-determined water 420 quality and duplicate samples collected using aseptic grab sampling. However, while autosamplers can reduce the resources needed for continual monitoring, maintaining the integrity of microbial populations in aquatic samples is essential for accurate and reproducible environmental monitoring. The results of our die-off experiment clearly demonstrated the advantage of refrigeration in maintaining concentrations of $E$. coli at levels close to their original magnitude at the point of sample collection. Up to 96 hours after collection the concentrations of $E$. coli did not differ significantly from concentrations at time 0. This finding complements the results reported by Ferguson (1994) whereby faecal coliform levels did not change throughout the 18 hour duration of monitoring in a refrigerated autosampler.

Concentrations of $E$. coli under ambient conditions changed more quickly relative to the refrigerated samples and differed from the initial concentration within only 12 hours of sample collection, but the difference related to an increase in cell numbers over time rather than an expected decline. This may be due to the high faecal matter content of the inoculum applied to each replicate bottle at the onset of the experiment which represented a heavily polluted water sample typical of stream water contaminated by faeces from direct defecation by grazing livestock. The high loading with organic matter coupled with the warm temperatures at times in excess of $20^{\circ} \mathrm{C}$, and protection from UV radiation, could have provided conditions conducive for supporting high numbers of $E$. coli and their subsequent replication. Growth of E. coli, including the pathogenic strain E. coli O157, in sterile freshwater with natural nutrients at low concentrations has been reported (Vital et al., 2008; Williams et al., 2012). However, while our study was carried out over a period of very warm weather in Scotland the average temperature over the first 24 hours was only $15^{\circ} \mathrm{C}$ compared with previous studies using temperatures more conducive for E. coli growth, e.g. $44430^{\circ} \mathrm{C}$ (Vital et al., 2008). The high faecal matter content and associated protective habitat and supply of nutrients could have provided conditions that enabled cell replication despite 
446 the suboptimal temperatures for cell growth (Shelton et al., 2014). Data reported by others

447 suggests that bottle-effects from short term (3 - $9 \mathrm{~h})$ or extended short term (3 - $24 \mathrm{~h})$ holding

448 in an autosampler under ambient conditions do not impact significantly on culturable

449 Enterococcus spp. counts (Ghazaleh et al., 2014). The extended short-term results contrast 450 with our finding for another FIO, E. coli, whereby significant differences from $\mathrm{T}_{0}$ 451 concentrations were observed after only 12 hours. This difference may relate to the different indicator organism under investigation, contrasting properties of the estuarine versus fresh water sources or could have been driven by variable temperature profiles associated with the two studies, though temperatures are not reported explicitly by Ghazaleh et al. (2014).

Results from the autosampler evaluation phase of this study reinforce some important issues regarding the collection of samples for microbial water quality sampling. If care is taken to sterilise autosampler bottles immediately before they are deployed then they can offer an effective method of sample acquisition, particularly in remote field locations during storm sampling campaigns. Others have shown that appropriate steps need to be taken to reduce residual FIO accumulation within autosampler inlet hoses (Hathaway et al., 2014). However, sample storage time in the autosampler unit needs careful consideration depending on the anticipated length of a sampling campaign. Storage beyond 12 hours inside a standard autosampler unit is likely to impact on FIO numbers in freshwater samples, reinforcing the importance of ensuring that field technicians are alerted via telecommunications (e.g. SMS) when an autosampler routine is initiated. Clearly, a key benefit of refrigeration is to shorten the length of the growth phase making this a more accurate method for sample collection if using an autosampler unit. Previous research has reported FIO concentrations from samples stored in an unrefrigerated autosampler unit for up to a week by applying a correction factor to account for the expected die-off rate of the target population (Vinten et al., 2008). By using this back calculation the authors retraced die-off curves to obtain the initial FIO concentration held in the sample collection bottle at $\mathrm{T}_{0}$.

472 While the rationale for such an approach may appear logical the opportunity for erroneously estimating FIO population change under field-relevant conditions is large. The results of our 
study urge caution on the use of such an approach, especially if samples are obtained in summer where ambient temperatures in bottles could reach in excess of $20^{\circ} \mathrm{C}$ as part of a diurnal cycle.

\section{Conclusion}

Low intensity $\left(<4 \mathrm{~mm} \mathrm{hr}^{-1}\right)$ rainfall events observed at headwater scales during summer months can increase FIO concentrations in small streams by an order of magnitude. While the absolute concentrations recorded in this study were low, this finding is important for demonstrating the transferability of rules of FIO behaviour whereby an increase in $Q$ observed in well-defined hydrographs moving from relatively 'low' to 'high' flow carries a signature of increasing $E$. coli concentrations. However, further research is needed to tease out the subtleties of E. coli-Q event dynamics across a breadth of different storm typologies while also disentangling any interference in microbial water quality signatures of large FIO sources (e.g. direct deposition) on concentration-Q responses, which is clearly a challenge in summer grazing seasons. The overall microbial load exported during low intensity rainfall events is much reduced (by up to four orders of magnitude, if not more) compared with high intensity rainfall events and particularly those that occur during periods of wetter weather and so the impact of these events is perhaps spatially constrained. Sampling methods can also affect the reporting of microbial water quality if storage of samples within autosampler units is not given proper consideration. Our study provides some assurance of minimal deterioration of sample quality when water is collected using an automatic sampler for subsequent microbiological analysis provided that samples are collected in a prompt fashion for return to the laboratory.

\section{Acknowledgements}

This study was part-funded by the UK Department for Environment, Food and Rural Affairs (Defra) in association with project WQ0129 and by the University of Stirling. The authors would like to acknowledge the valuable and insightful contribution of the participating farmers 
and are particularly grateful for land access permissions. Finally, the constructive comments from two anonymous referees helped to improve the overall quality of this manuscript.

\section{References}

Altman, D. G. \& Bland, J. M. (1983). Measurement in medicine: the analysis of method comparison studies. The Statistician 32: 307-317.

Arnell NW, Halliday SJ, Battarbee RW, Skeffington RA, Wade AJ (2015). The implications of climate change for the water environment in England. Progess in Physical Geography 39: 93-120

Bilotta, G.S. Krueger, K.T., Brazier, R.E., Butler, P., Freer, J., Hawkins, J.M.B., Haygarth, P.M., Macleod, C.J.A., \& Quinton, J.N. (2010). Assessing catchment-scale erosion and yields of suspended sediment from improved temperate grassland. Journal of Environmental Monitoring, 12, 731-739.

CEC (2006). Council Directive 2006/7/EC of the European Parliament and of the council of $15^{\text {th }}$ February 2006 concerning the management of bathing water quality and repealing Directive 76/160/EEC. Official Journal of European Union L64, 37-51.

Davies-Colley, R., Lydiard, E. \& Nagels, J. (2008). Stormflow-dominated loads of faecal pollution from an intensively dairy-farmed catchment. Water Science and Technology, 57, 1519-1523.

Environment Agency (2009). The Microbiology of Drinking Water Part 4 - methods for the Isolation and Enumeration of Coliform Bacteria and Escherichia coli (including E. coli O157:H7). Standing Committee of Analysts 2009; The Environment Agency: Bristol, 104pp.

Ferguson, C.M. (1994). Refrigerated autosampling for the assessment of bacteriological water quality. Water Research, 28, 841-847.

Fish, R.D., Winter, M., Oliver, D.M., Chadwick, D.R., Hodgson, C.J. and Heathwaite, A.L. (2014). Employing the citizens' jury technique to elicit reasoned public judgements about environmental risk: insights from an inquiry into the governance of microbial water pollution. Journal of Environmental Planning \& Management, 57, 233-253.

Fish, R.D., Winter, M., Oliver, D.M., Chadwick, D.R., Selfa, T., Heathwaite, A.L. \& Hodgson, C.J. (2009). Unruly pathogens: eliciting values for environmental risk in the context of heterogeneous expert knowledge. Environmental Science \& Policy, 12, 281-296.

Ghazaleh, M.N., Froelich, B.A., and Noble, R.T. (2014). The effect of storage time on Vibrio spp. and fecal indicator bacteria in an ISCO autosampler. Journal of Microbiological Methods, 104, 109-116.

Granger, S.J., Bol, R., Hawkins, J.M.B., White, S.M., Naden, P.S., Old, G.H., Marsh, J.K., Bilotta, G.S., Brazier, R.E., Macleod, C.J.A., \& Haygarth, P.M. (2011). Using artificial fluorescent particles as tracers of livestock wastes within an agricultural catchment. Science of the Total Environment, 409, 1095-1103. 
Guber, A. K., Pachepsky, Y. A., Yakirevich, A. M., Shelton, D. R., Sadeghi, A. M., Goodrich, D. C., and Unkrich, C. L. (2011). Uncertainty in modelling of faecal coliform overland transport associated with manure application in Maryland. Hydrological Processes, 25, 23932404.

Harris, G. P., \& Heathwaite, A. L. (2012). Why is achieving good ecological outcomes in rivers so difficult? Freshwater Biology, 57, 91-107.

Hathaway, J. M., Hunt, W. F., Guest, R. M., and McCarthy, D. T. (2014). Residual indicator bacteria in autosampler tubing: a field and laboratory assessment. Water Science \& Technology, 69, 1120-1125.

Haygarth, P. M., Page, T. J. C., Beven, K. J., Freer, J., Joynes, A., Butler, P., Wood, G. A. and Owens, P. N. (2012). Scaling up the phosphorus signal from soil hillslopes to headwater catchments. Freshwater Biology, 57, 7-25.

Hodgson C.J., Bulmer N., Chadwick D.R., Oliver D.M., Heathwaite A.L., Fish R.D., \& Winter M. (2009). Establishing relative release kinetics of faecal indicator organisms from different faecal matrices. Letters in Applied Microbiology, 49, 124-130.

Kay, D., Anthony, S., Crowther, J., Chambers, B. J., Nicholson, F. A., Chadwick, D. Stapleton, C.M. \& Wyer, M. D. (2010). Microbial water pollution: a screening tool for initial catchment-scale assessment and source apportionment. Science of the Total Environment, 408, 5649-5656.

Kay, D., Crowther, J., Fewtrell, L., Francis, C. A., Hopkins, M., Kay, C., McDonald, A. T., Stapleton, C. M., Watkins, J., and Wyer, M. D. (2008). Quantification and control of microbial pollution from agriculture: a new policy challenge? Environmental Science \& Policy 11, 171184.

Kay, D., Edwards, A.C., Ferrier, R.C., Francis, C., Kay, C., Rushby, L., Watkins, J., McDonals, A.T., Wyer, M., Crowther, J. \& Wilkinson, J. (2007). Catchment microbial dynamics: the emergence of a research agenda. Progress in Physical Geography, 31, 5976 .

Kay, D., Wyer, M.D., Crowther, J., O’Neill, J.G., Jackson, G., Fleisher, J.M. and Fewtrell, L. (1999). Changing standards and catchment sources of faecal indicators in nearshore bathing waters. In Trudgill, S., Walling, D. and Webb, B., editors, Water quality processes and policy, Chichester: Wiley, 47-64.

McDaniel, R. L., Soupir, M. L., Tuttle, R. B., \& Cervantes, A. E. (2013). Release, dispersion and resuspension of Escherichia coli from direct fecal deposits under controlled flows. Journal of the American Water Resources Association, 49, 319-327.

McKergow, L.A. \& Davies-Colley, R.J. (2010). Stormflow dynamics and loads of Escherichia coli in a large mixed land use catchment. Hydrological Processes, 24, 276-289.

Meays C. L., Broersma, K., Nordin, R., Mazumder, A., and Samadpour, M. (2006). Spatial and annual variability in concentrations and sources of Escherichia coli in multiple watersheds. Environmental Science and Technology 40, 5289-5296. 
MET Office (2009). Radar: National Meteorological Library and Archive Fact sheet 15 Weather radar. http://www.metoffice.gov.uk/media/pdf///h/Fact sheet No. 15.pdf. Accessed 2/12/14.

Muirhead, R. W., Davies-Colley, R. J., Donnison, A. M., \& Nagels, J. W. (2004). Faecal bacteria yields in artificial flood events: quantifying in-stream stores. Water Research, 38, 1215-1224.

Oliver, D.M., Page, T., Hodgson, C.J., Heathwaite, A.L. Chadwick, D. R., Fish, R.D. and Winter, M. (2010). Development and testing of a risk indexing framework to determine fieldscale critical source areas of faecal bacteria on grassland. Environmental Modelling and Software, 25, 503-512.

Oliver, D. M, Clegg, C.D. Haygarth, P.M. \& Heathwaite, A. L. (2005a). Assessing the potential for pathogen transfer from grassland soils to surface waters. Advances in Agronomy, 85, 125-180.

Oliver, D.M., Heathwaite, L., Haygarth, P.M. \& Clegg, C.D. (2005b). Transfer of Escherichia coli to water from drained and undrained grassland after grazing. Journal of Environmental Quality, 34, 918-925.

Owen, G.J., Perks, M.T., Benskin, C.M.H., Wilkinson, M.E., Jonczyk, J., \& Quinn, P.F. (2012). Monitoring agricultural diffuse pollution through a dense monitoring network in the River Eden Demonstration Test Catchment, Cumbria, UK. Area, 44.4, 443-453.

Pachepsky, Y. A. and Shelton, D. R. (2011). Escherichia coli and fecal coliforms in freshwater and estuarine sediments. Critical Reviews in Environmental Science \& Technology, 41, 1067-1110.

R Core Team (2012). R: A language and environment for statistical computing. $R$ Foundation for Statistical Computing, Vienna, Austria. ISBN 3-900051-07-0, URL http://www.R-project.org/

Rozen, Y., \& Belkin, S. (2001). Survival of enteric bacteria in seawater. FEMS Microbiology Reviews, 25, 513-529.

Shelton, D. R., Pachepsky, Y. A., Kiefer, L. A., Blaustein, R. A., McCarty, G. W., \& Dao, T. $\mathrm{H}$. (2014). Response of coliform populations in streambed sediment and water column to changes in nutrient concentrations in water. Water Research, 59, 316-324.

Soil Survey of Scotland Staff. (1970-1987). Soil maps of Scotland (partial coverage) at a scale of 1:25 000. Macaulay Institute for Soil Research, Aberdeen.

Solo-Gabriele, H. M., Wolfert, M. A., Desmarais, T. R., and Palmer, C. J (2000). Sources of Escherichia coli in a coastal subtropical environment. Applied \& Environmental Microbiology, 66, 230-237.

Stadler, H., Skritek, P., Sommer, R., Mach, R. L., Zerobin, W., and Farnleitner, A. H. (2008). Microbiological monitoring and automated event sampling at karst springs using LEOsatellites. Water Science \& Technology, 58, 899-909. 
Vinten, A. J. A., Sym, G., Avdic, K., Crawford, C., Duncan, A. and Merrilees, D. W. (2008). Faecal indicator pollution from a dairy farm in Ayreshire, Scotland: source apportionment,

Vital, M., Hammes, F \& Egli, T. (2008). Escherichia coli 0157 can grow in natural freshwater at low carbon concentrations. Environmental Microbiology, 10, 2387-2396.

White, S. L., Sheffield, R. E., Washburn, S. P., King, L. D., and Green, J. T. (2001). Spatial and time distribution of dairy cattle excreta in an intensive pasture system. Journal of Environmental Quality, 30, 2180-2187.

Wilkes, G., Edge, T., Gannon, V., Jokinen, C., Lyautey, E., Medeiros, D., Neumann, N., Ruecker, N., Topp, E., Lapen, D. R. (2009). Seasonal relationships among indicator bacteria, pathogenic bacteria, Cryptosporidium oocysts, Giardia cysts and hydrological indices for surface waters within an agricultural landscape. Water Research, 43, 2209-2223.

Wilkinson, R. J., McKergow, L. A., Davies-Colley, R. J., Ballantine, D. J., \& Young, R. G. (2011). Modelling storm-event $E$. coli pulses from the Motueka and Sherry rivers in the South Island, New Zealand. New Zealand Journal of Marine \& Freshwater Research, 45, 369-393.

Williams, A.P., Quilliam, R.S., Thorn, C., Cooper, D., Reynolds, B., \& Jones D.L. (2012). Influence of land use and nutrient flux on metabolic activity of Escherichia coli $\mathrm{O} 157$ in river water. Water, Air \& Soil Pollution 223: 3077-3083

Winter, M., Oliver, D.M., Fish, R., Heathwaite, A. L., Chadwick, D., \& Hodgson, C. (2011). Catchments, subcatchments and private spaces: scale and process in managing microbial pollution from source to sea. Environmental Science \& Policy, 14, 315-326.

Wyer, M.D., Kay, D., Watkins, J., Davies, C., Kay, C., Thomas, R., Porter, J., Stapleton, C.M., Moore, H. (2010). Evaluating short-term changes in recreational water quality during a hydrograph event using a combination of microbial tracers, environmental microbiology, microbial source tracking and hydrological techniques: a casestudy in Soutwest Wales, UK. Water Research, 44, 4783-4795. 


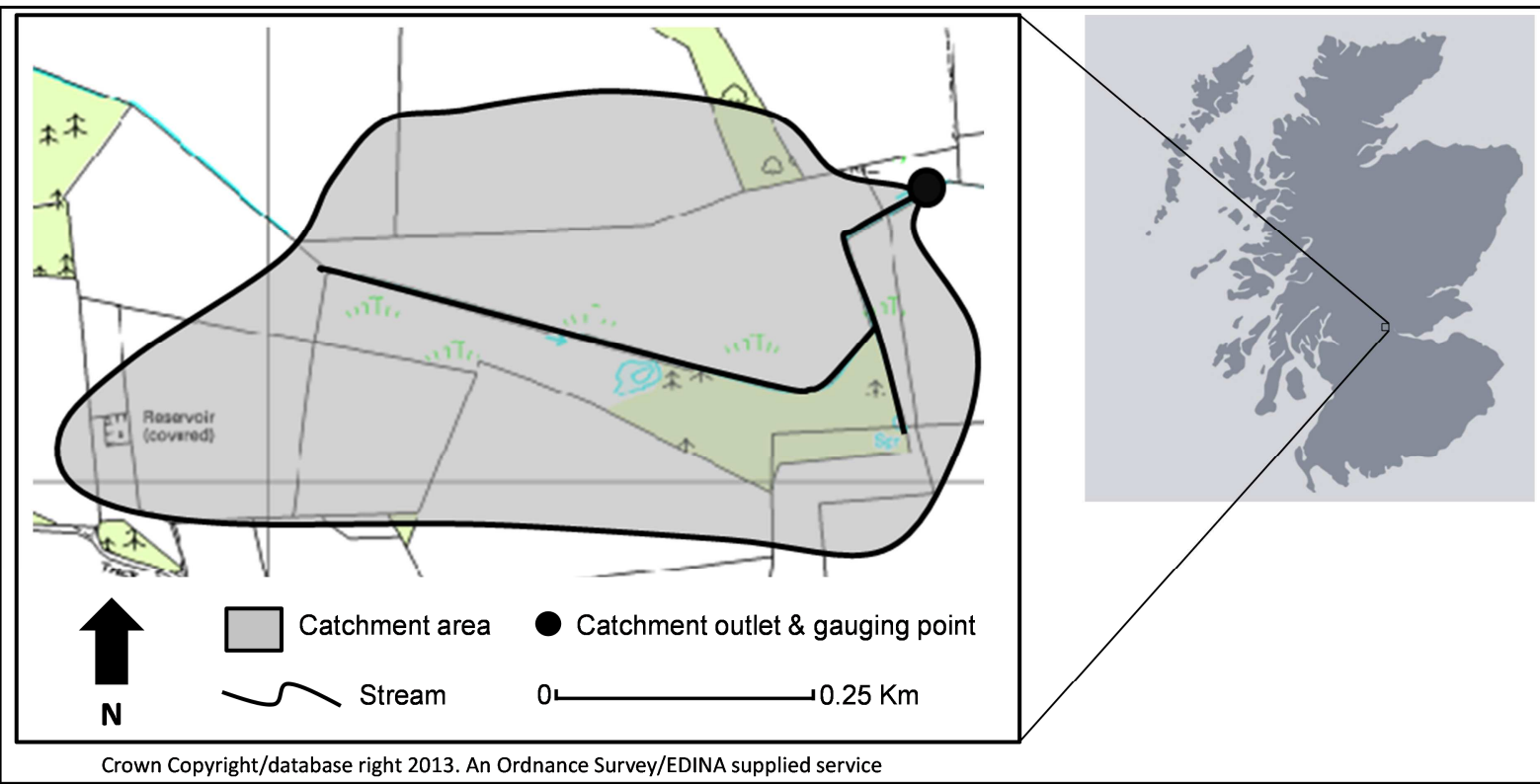

683

Crown Copyright/database right 2013. An Ordnance Survey/EDINA supplied service

684 Figure 1: Location and area of the study catchment

685

686

687

688

689 


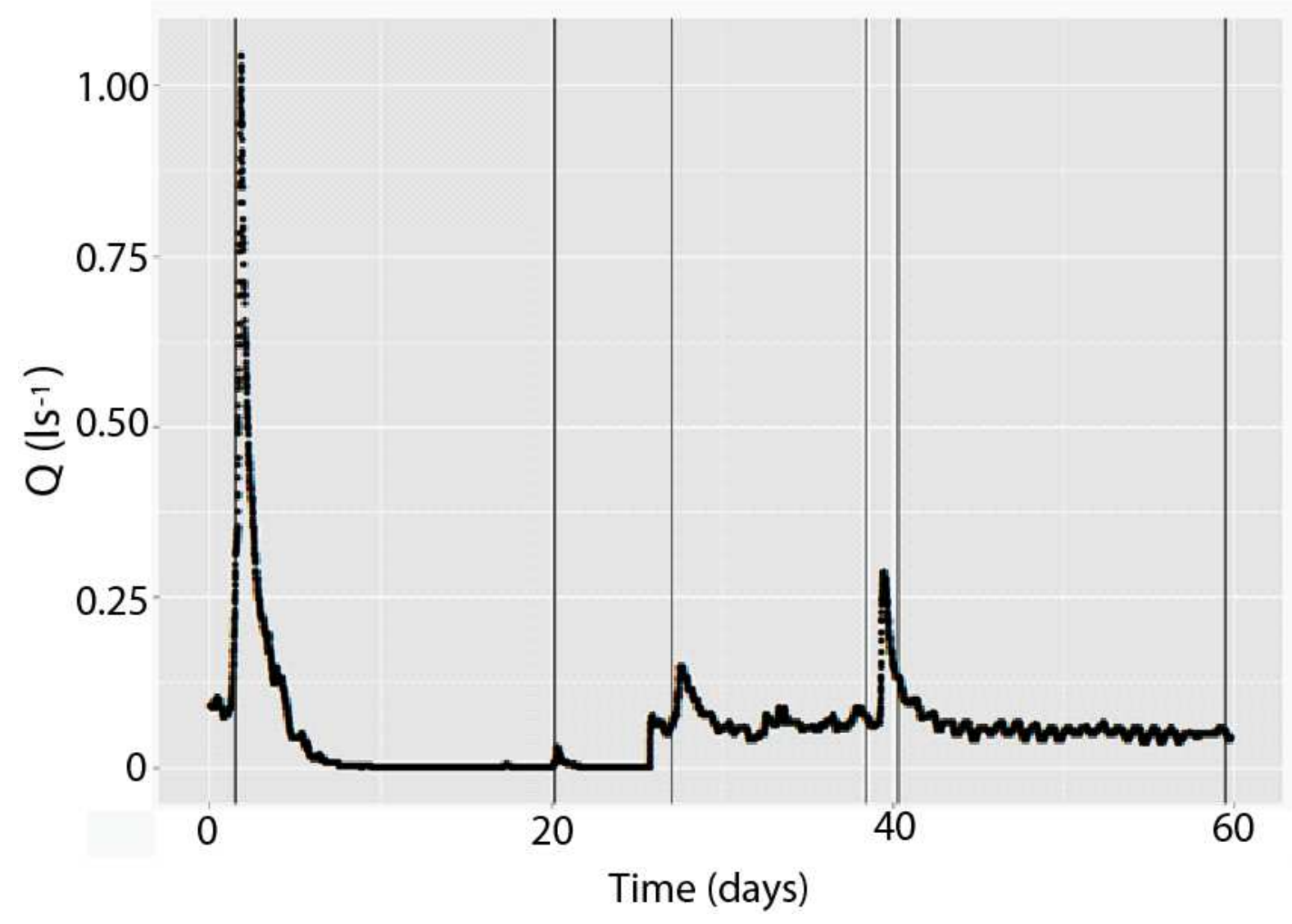

691

Figure 2: Hydrograph of the entire study period with vertical lines indicating when the first sample of each event was captured. Events 1-6 are sequential in their occurrence.

693

694

695

696

697

698

699

700 


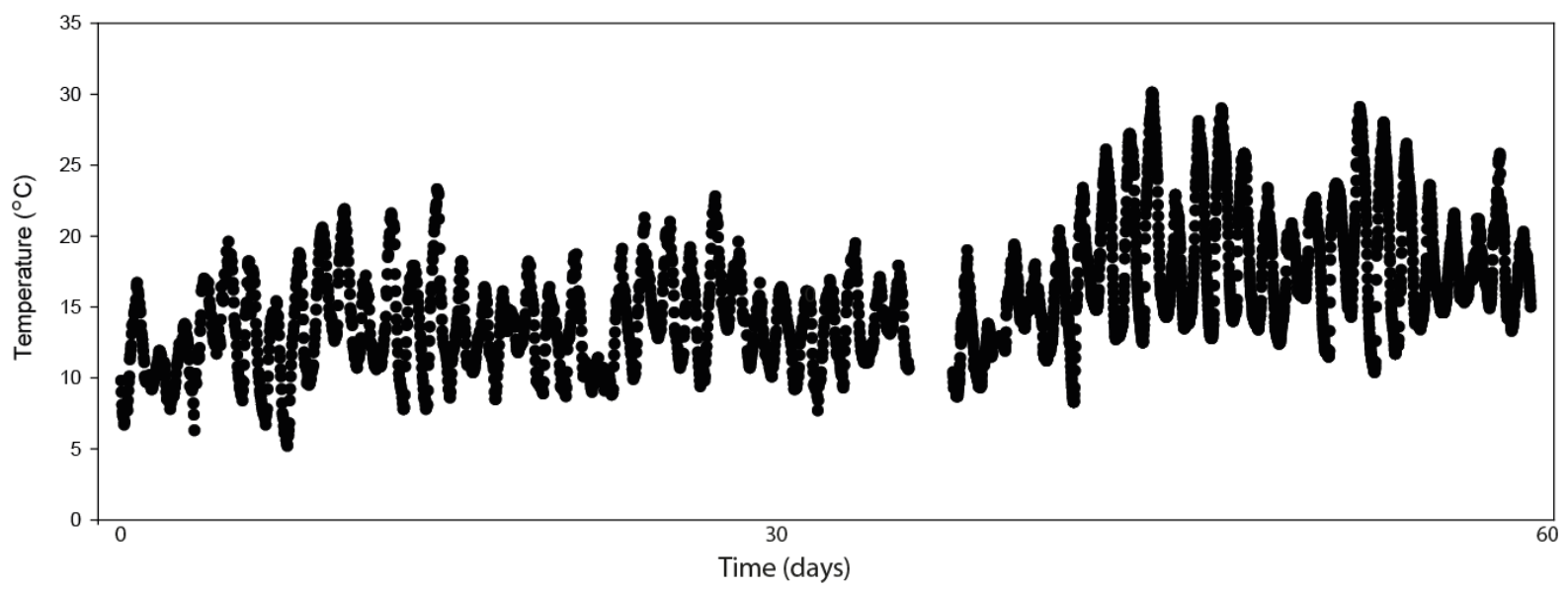

701

Figure 3: Air temperature profile of the study period

703

704

705

706

707

708

709

710

711

712

713

714

715

716

717

718

719

25 

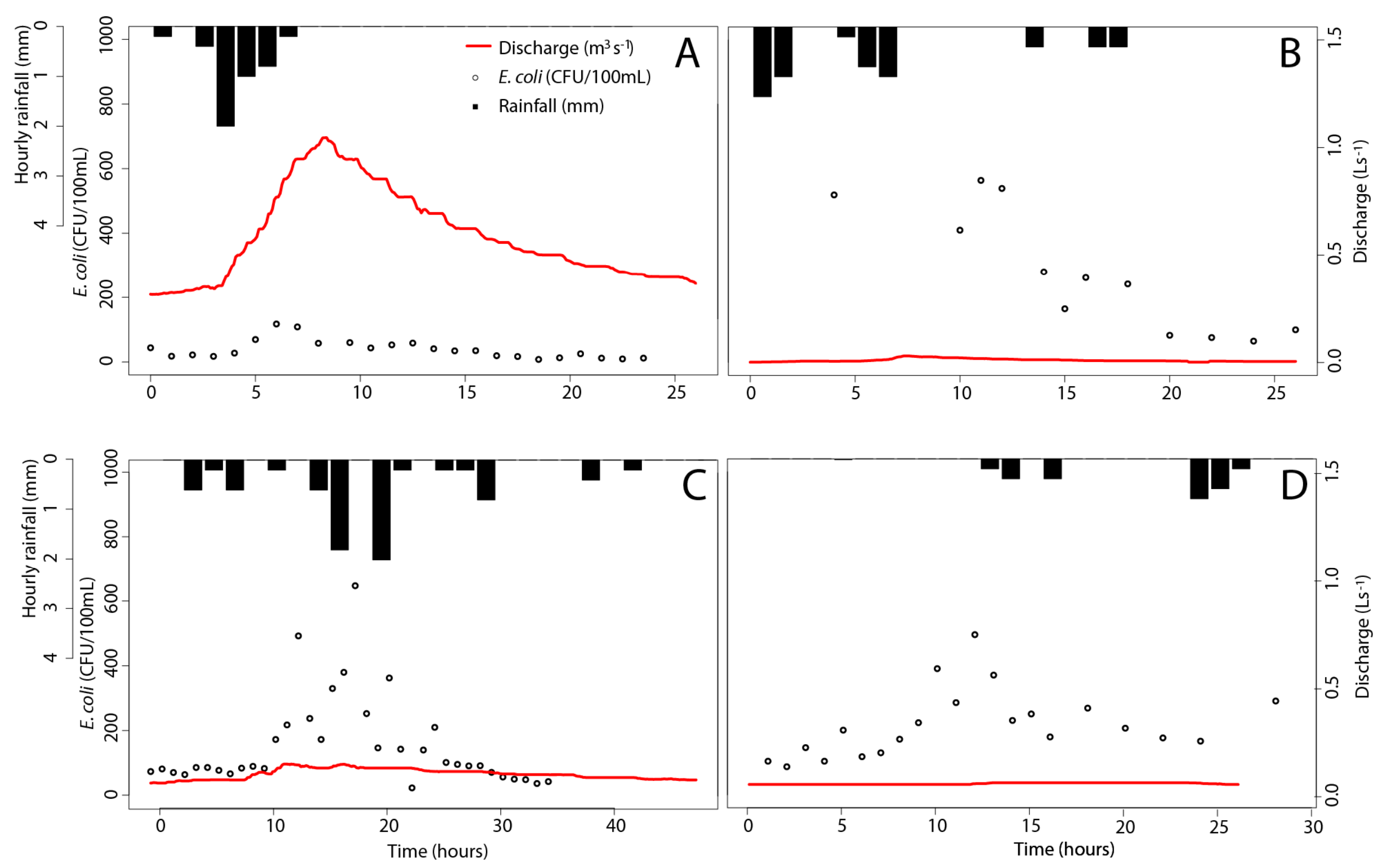


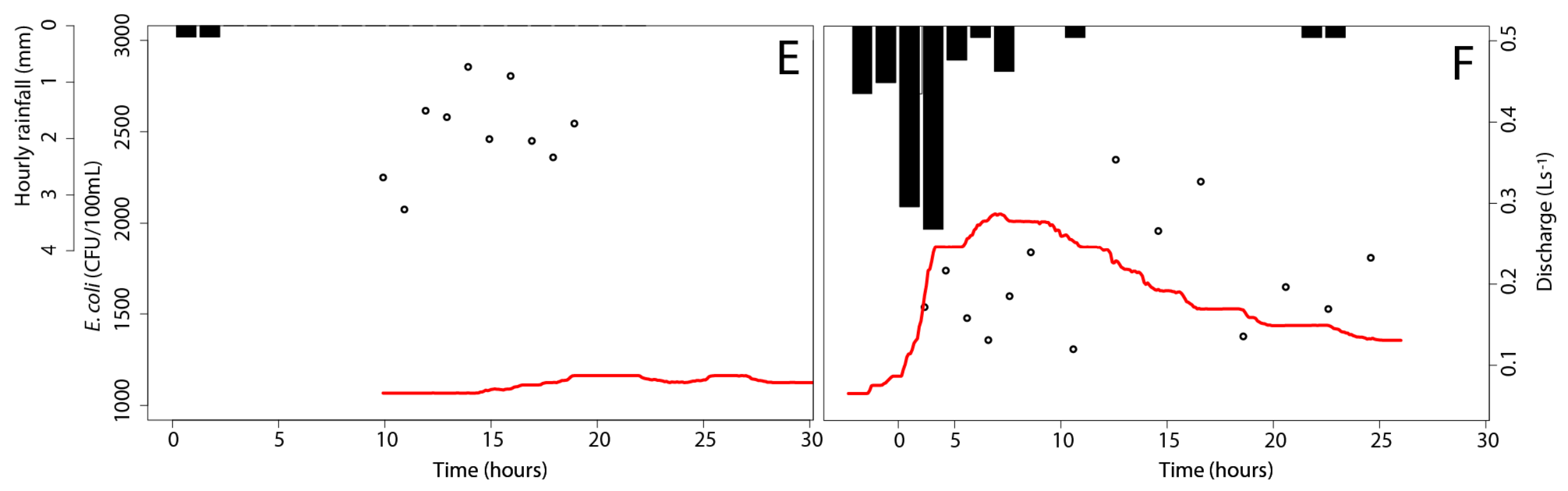

Figure 4: (a) to (d) show E. coli (circles) and $\mathrm{Q}$ (red line) during events 1, 2, 3, and 6, respectively; (e) and (f) show E. coli and $\mathrm{Q}$ for events 4 and 5, respectively. Note the differing scales for both $E$. coli and $Q$ between plots (a) to (d) and (e) \& (f). 


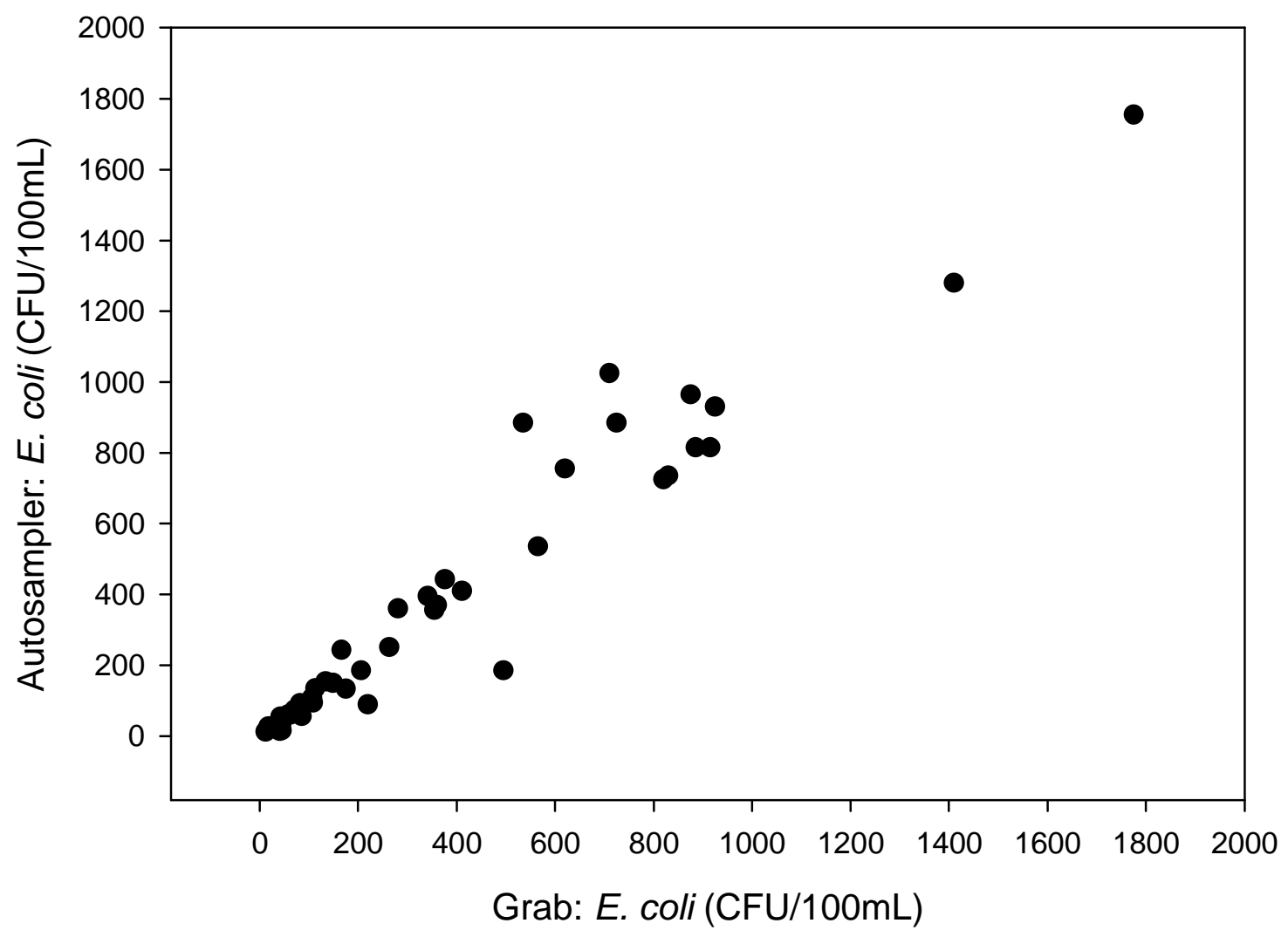

Figure 5. Comparison of E. coli concentrations derived from autosampler and manual grab sampling. 


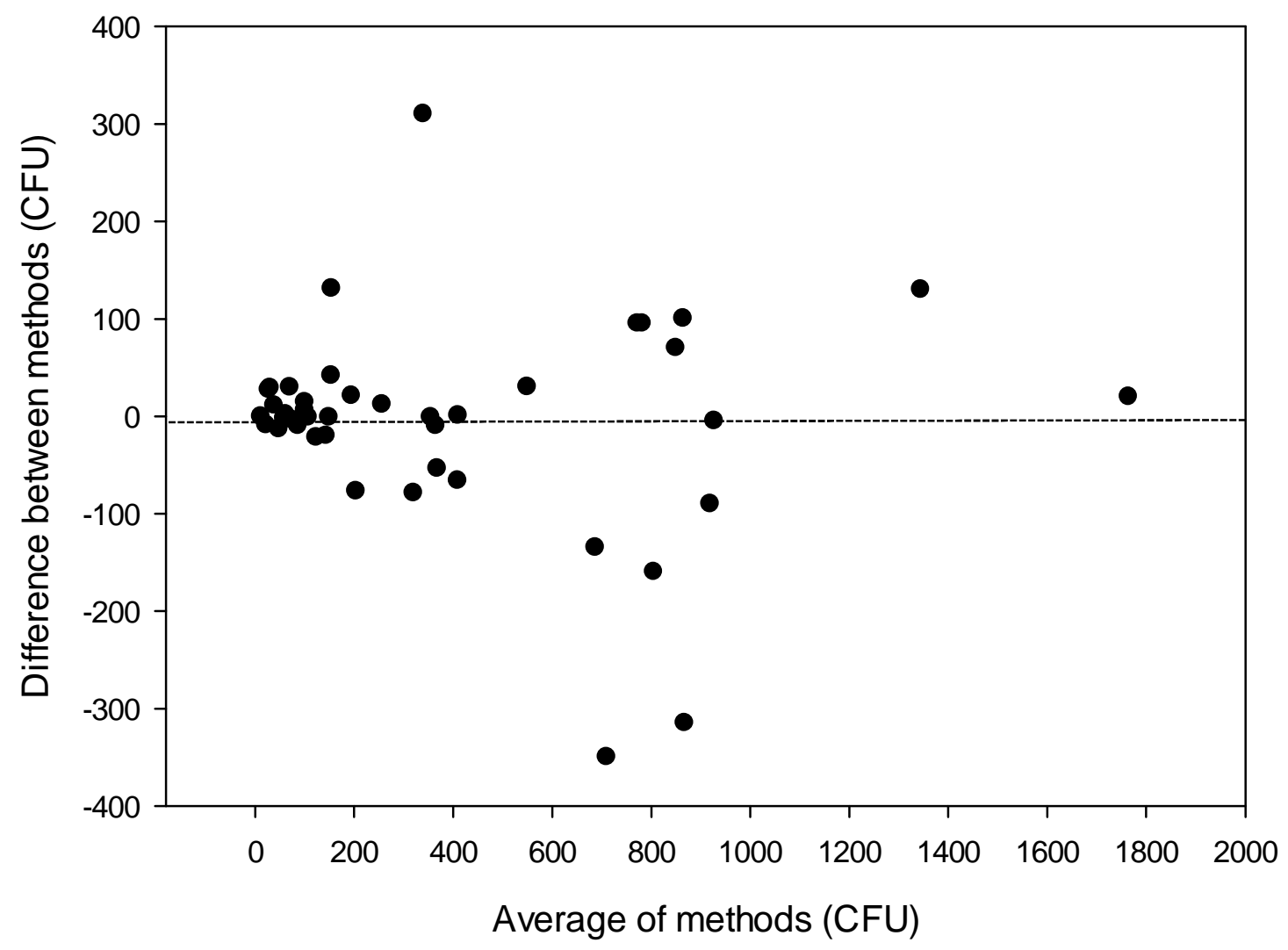

Figure 6. Difference in CFUs determined using the grab and autosampler methods versus the average CFUs determined using both methods. Dashed line represents relative bias (mean of the differences across all paired samples; -5.9) 


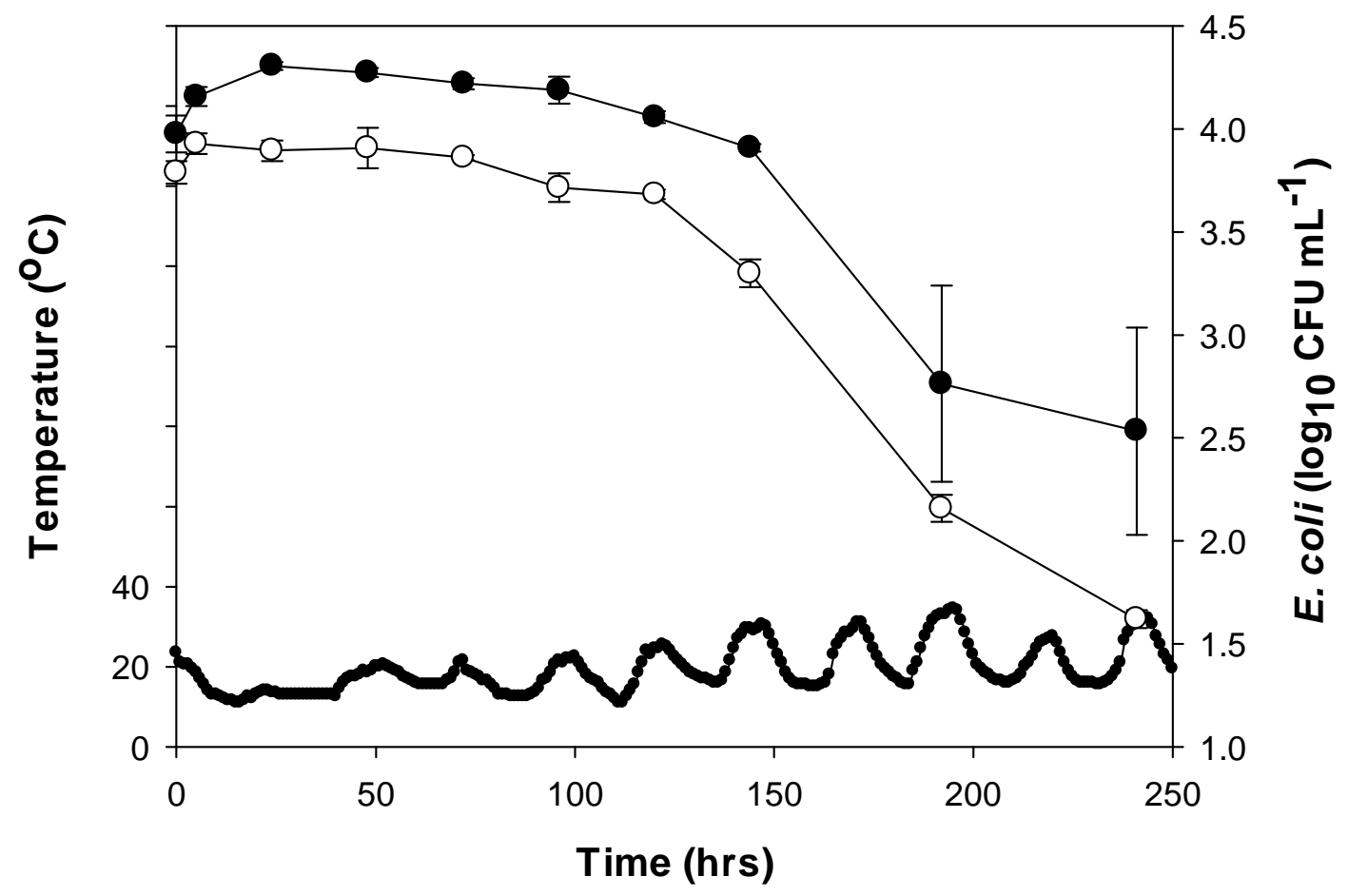

Figure 7. E. coli persistence over time under ambient (solid circles) and refrigerated $\left(4^{\circ} \mathrm{C}\right.$; hollow circles) conditions. Ambient temperature fluctuations inside autosampler unit depicted by via black line) 
Table 1. Summary characteristics for the six 'events' investigated.

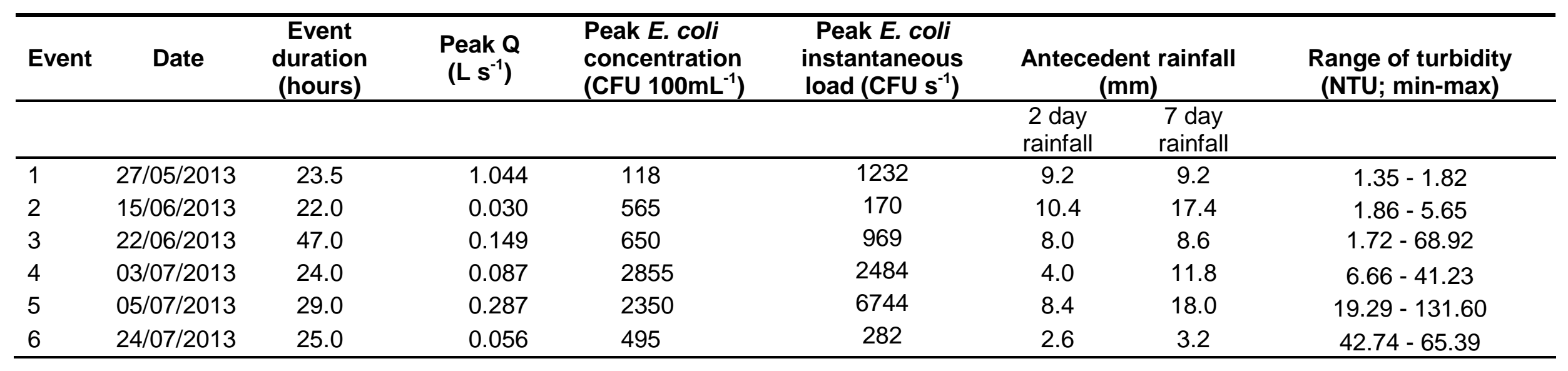


Table 2: Decline rate constants for $E$. coli, reflecting the two observed die-off phases of the $E$. coli population dynamics. The $p$ value shows the results of a Mann-Whitney-Wilcoxon test investigating whether there were significant differences between the decline rates of each treatment at each phase.

\begin{tabular}{lcc}
\hline \multirow{2}{*}{ Treatment temperature } & \multicolumn{2}{c}{ Modelled linear rate constant } \\
\cline { 2 - 3 } & slow die-off $\left(\mathbf{h r}^{-1}\right)^{\mathbf{a}}$ & rapid die-off $\left(\mathbf{h r}^{-1}\right)^{\mathbf{a}}$ \\
\hline Fluctuating ambient & -0.0037 & -0.0143 \\
Constant refrigerated & -0.0045 & -0.0173 \\
$p$ value & $>0.05$ & 0.03 \\
\hline
\end{tabular}

